\title{
AINTSHOP PRODUCTION LINE OPTIMIZATION USING RESPONSE SURFACE METHODOLOGY
}

\author{
Berna Dengiz \\ Baskent University \\ Department of Industrial Engineering \\ Baglica campus, Eskisehir Road \\ 06530 Ankara, TURKEY
}

\author{
Onder Belgin \\ National Productivity Center of Turkey, \\ Gelibolu Street No:5 \\ 06690 Kavaklidere, Ankara, TURKEY
}

\begin{abstract}
This paper deals with the problem of determining the optimum number of workstations to be used in parallel and workers at some stations using simulation optimization approach in a paint shop line of an automotive factory in Ankara, Turkey. In the optimization stage of the study Response Surface Methodology (RSM) is used to find the optimum levels of considered factors. Simulation model and optimization stage integration is used both to analyse the performance of the current paint shop line and determine the optimum working conditions, respectively, with reduced cost, time and effort.
\end{abstract}

\section{INTRODUCTION}

Increasing consumer demands and today's global competence forces firms to find new ways to produce the products faster, cheaper and more effectively. Because of the complex stochastic characteristics of systems, simulation is the powerful tool to investigate their behavior and the effects of design factors on system performance.

This study demonstrates how Response Surface Methodology (RSM) is used in practice to find the optimum levels of design factors to ensure a well-designed physical system. In other words, simulation model and optimization stage integration is used both to analyze the performance of the current paint shop line to reveal the bottlenecks at some stages and determine the optimum working conditions, respectively, with reduced cost, time and effort. Validated simulation outputs are collected and used to build a response surface multiple regression meta-model.

Biles and Kleijnen (1999), Nicolai et al. (2004), Allen and Yu (2000), Stewart, Fleming, and MacKenzie (2002) used RSM in their studies for finding optimum combination of factor levels. Schamburg and Brown (2004a) proposed a methodology that includes the complementary use of simulated annealing and RSM for analysis of simulation. Schamburg and Brown (2004b) generalize the traditional

RSM to complex, multi-objective simulation studies. Angün et al. (2002) presented a new RSM combined adapted steepest descent in the first-order polynomial phase to prevent scale dependence disadvantage of steepest descent. Kenne and Gharbi (2001) proposed a new method to control the production rate of manufacturing system using the combination of stochastic optimal control theory, discrete event simulation and RSM.

\section{PAINT SHOP SIMULATION MODELING}

In this study, the paintshop line of an automotive factory in Turkey with highly complex system flow shown in Figure 1 is considered.

Painting is the main process of this production system after the skeleton assembly in this automotive factory. The company produces 2 main types of vehicles; city buses and coaches. Each of these vehicles can also be classified into 2 types in terms of their design differences. Each vehicle type has also opaque or metallic coloring options. Thus, eight different types of vehicles are processed in this paintshop.

While the vehicles are assembled on the skeleton assembly through 2 shifts, paintshop works with 3 shifts a day. However, in the third shift the number of workers is decreased in some of the workstations so processing times varies. The sequence of the station is known as well as the statistical distribution of processing times at each station. The processing times are valid for the first two shifts. There is an inverse proportion relation between the number of workers and operation times. That is, operation times increase when the number of workers decreases. 


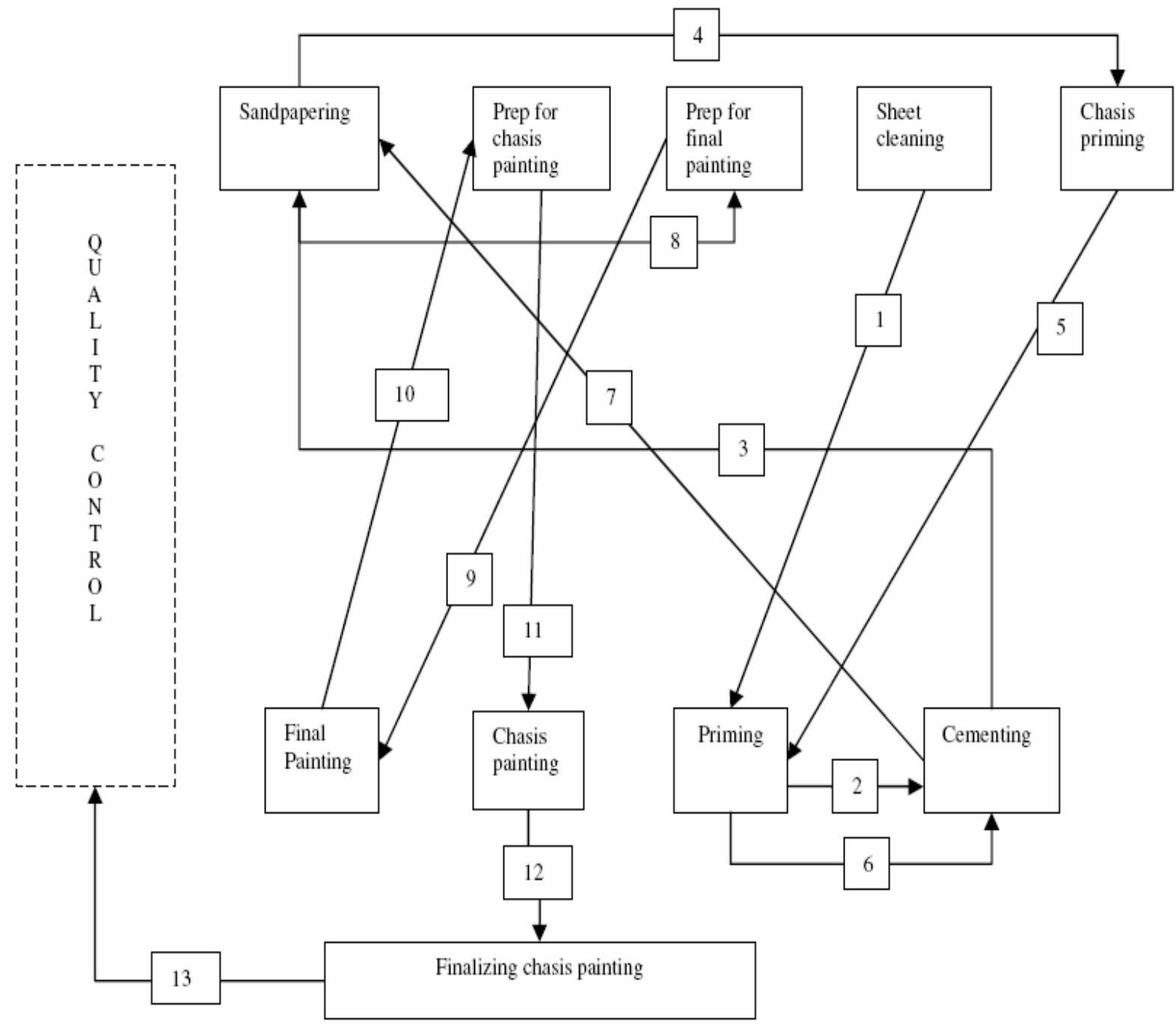

Figure 1. System flow between workstations

Paintshop is multi-stage series production line with multiple workers for tasks assigned at each station. The production line in the paintshop consist of eleven stationsnamed sheet cleaning, priming,, cementing, sandpapering, Chassis priming, Prep for final painting, Final Painting, Prep for chassis painting, Chassis painting, Finalizing chassis painting, and quality control- where some stations are responsible more than one task so totally fourteen tasks are carried out by different number of workers depends on task type. These are sheet cleaning, prime painting $I, c e-$ menting I, sandpapering I, chassis priming, priming II, cementing II, sandpapering II, prep for final painting, final painting; prep for chassis painting, chassis painting; finalizing chassis painting, and quality control with workers 11 , $2,7,14,3,2,3,12,4,2,9,2,3,8$, respectively for during first two shifts. They are reduced for third shifts as ; 7, 2, 5, $9,2,2,2,8,3,2,6,2,2,6$. After the quality control, if there is a painting defect on the vehicle it is sent to the stations in the sequence of sandpapering, prep for final painting and final painting workstations for repaint. Due to the defective paint of the buses nearly $25 \%$ of them go back for repaint.

The company aim is to release at least 10 buses in a day. However, the paint shop releases average 9.1 buses in a day with the current manufacturing resources. In our approach, a simulation model is built for the series of stations using discrete-event simulation. In the modeling stage, ARENA (Kelton, Sadowski, and Sadowski 1998) is used considering each shift (450 min. $=7.5$ hours) with different simulation scenarios. To measure the steady-state mean of system performance -throughput rate- we used batch means method based on a single enough long run. The simulation run length is totally 922.5 hours (41 days) including 247.5 hours (11 days) warm-up period and 30 batches 
with 22.5 hours (three shifts) enough batch length. According to Law (2007), triangular distribution approach is used to model of task times based on a few actual data and also expert opinions. Simulation results show that priming, final painting and quality control stations are bottlenecks of this system, i.e., these processes have a large amount of workin-process. For this reason, the number of workers for quality control station, the number of workstations for final painting and priming are the main factors of system productivity.

\section{RESPONSE SURFACE METHODOLOGY}

Recently, RSM has a wide application area in quality and industrial engineering for the design of a new product, the redesign of existing product or the development of a new product. It is a collection of statistical and mathematical techniques and useful for optimizing stochastic functions such as simulation model which explains relation between inputs and output, i.e., response of interest. The managers of any company need to have a robust understanding of the impact of both operational and environmental variables and their interactions on system throughput. For the optimization of stochastic simulation models there is a vast amount of published papers and tutorials using gradient based searched methods, stochastic optimization, RSM, modern heuristic methods, a-teams, statistical methods (Carson and Maria 1997). Compared to many gradient based methods, RSM is a relatively efficient method of simulation optimization in terms of the number of simulation experiments required and this method is never more complicated than the other methods mentioned, in contrast its application is not time-consuming., i.e., it needs less simulation time.

The stages of RSM are follows; First, the preliminary work in which the selection of the input variables (factors) and their levels are carried out. Second stage is the selection of experimental design to obtain minimum variances of the responses and making simulation runs considering the experimental design conditions. Third stage is to build first or higher order regression metamodel and surface fitting (the response surface plot and counter plot of the responses) to obtain approximate responses and the prediction and verification of the model equation. Final stage is the optimization of approximated responses which is called inverse analysis.

RSM is suggested by Box and Wilson (1951) and developed by Box, Hunter and Hunter (1978). This method is essentially an empirical method and aims to find the best value of the response. If the best value of the response exceeds the resources of the experiment this method is used to obtain better result from the response system. The regression surface fitting can be divided into two main phases. First phase, includes a first order regression model. Using this first order model explorations are made along a gradient vector. The stopping criterion of this phase is inadequacy of the first order regression model. Second phase differs from first phase usage of a second or higher order regression model.

\section{CASE STUDY}

As stated in Section 3 the first stage for this study is the preliminary work in which the selection of the input variables (factors) and their levels are carried out. Because it is not possible to identify the effect of all variables, it is important to determine the variables that have major effects on the response. Screening simulation experiments are used to identify the variables (factors) to be optimized. For this problem, these factors are determined based on both the performance measure of the simulation model (average number in queue statistics) and the opinion of the factory management. These factors are as follows:

- Number of workers in the quality control workstation

- Number of final painting workstation

- Number of priming workstation

Table 1: Factor levels and codes for design of experiment

\begin{tabular}{|l|c|c|c|c|}
\hline \multicolumn{1}{|c|}{ Factors } & $\begin{array}{c}\text { Min. } \\
\text { Lev. }\end{array}$ & $\begin{array}{c}\text { Max } \\
\text { Lev. }\end{array}$ & $\begin{array}{c}\text { Min. } \\
\text { Cod. }\end{array}$ & $\begin{array}{c}\text { Max } \\
\text { Cod. }\end{array}$ \\
\hline $\begin{array}{l}\text { Number of workers in the quality } \\
\text { control workstation }\left(\mathrm{x}_{1}\right)\end{array}$ & 8 & 12 & -1 & 1 \\
\hline $\begin{array}{l}\text { Number of final painting worksta- } \\
\left.\text { tions ( } \mathrm{x}_{2}\right)\end{array}$ & 1 & 3 & -1 & 1 \\
\hline $\begin{array}{l}\text { Number of priming workstations } \\
\left(\mathrm{x}_{3}\right)\end{array}$ & 1 & 3 & -1 & 1 \\
\hline
\end{tabular}

Then another important issue is the determination of factor levels that are related to the physical and economical conditions of the system. Allowable minimum and maximum levels of the factors are shown in Table 2. The RSM combined with a $2^{3}$ full factorial experimental design is used to show the relationship between response function that represent system output and factors that represent system inputs in which a response of interest is influenced by factors and the aim is to optimize this response. In other words, the aim of RSM is the determination of the optimum operating conditions of number of workers in the quality control workstation, number of final painting workstation, number of priming workstation in the Paintshop. Two central points are added to estimate the experimental error and to investigate the fitness of the metamodel.

After the first stage of this optimization approach, the following step is to make replications of simulation model considering all configuration of the factor levels through 
selected design of experiment. The first order regression metamodel is built for the approximation.

Table 2: $2^{3}$ factorial design

\begin{tabular}{|l|l|l|l|l|}
\hline $\begin{array}{l}\text { Desg. of } \\
\text { Exp. } \\
\text { Points }\end{array}$ & $\mathrm{x}_{1}$ & $\mathrm{x}_{2}$ & $\mathrm{x}_{3}$ & $\begin{array}{l}\text { Ave. Daily Output } \\
\text { (Number of Buses) }\end{array}$ \\
\hline 1 & -1 & -1 & -1 & 8.67 \\
\hline 2 & 1 & -1 & -1 & 9.00 \\
\hline 3 & 0 & 0 & 0 & 10.90 \\
\hline 4 & -1 & -1 & 1 & 9.47 \\
\hline 5 & 1 & 1 & 1 & 10.70 \\
\hline 6 & 1 & 1 & -1 & 10.70 \\
\hline 7 & -1 & 1 & 1 & 9.93 \\
\hline 8 & 1 & -1 & 1 & 7.60 \\
\hline 9 & -1 & 1 & -1 & 9.27 \\
\hline 10 & 0 & 0 & 0 & 10.50 \\
\hline
\end{tabular}

\section{1 $\quad$ First Order Model}

To fit the results of $2^{3}$ full factorial experimental design the first order model is used as shown below:

$$
Y=\beta_{0}+\sum_{i=1}^{k} \beta_{i} x_{i}+\varepsilon
$$

Where $\mathrm{Y}$ is simulation model response which estimates system output, $\beta_{0}$ is the intercept, $\beta_{\mathrm{i}}$ is linear coefficient. These coefficients $\left(\beta_{0}, \beta_{1}, \ldots, \beta_{\mathrm{k}}\right)$ are determined by least square methods. Table 2 represents average daily outputs (number of buses) of totally ten configuration points of factor levels (eight of them come from $2^{3}$ full factorial design, two from center points). Ten replications are performed of each design configuration.

The first order model of this design is:

$$
Y=9.65+0.083 x_{1}+0.732 x_{2}+0.007 x_{3}
$$

To see the validity of the model Lack of fit, F tests are used. The ANOVA results are seen in Table 5.

Since 1.57 doesn't exceed $\mathrm{F}_{(3,6,0.05)}=4.76$ the null hypothesis that states the first order coefficients are insignificant is not rejected. The determination coefficient that represents the overall performance of the model denoted by $\mathrm{R}^{2}$ is $44 \%$. Although the lack of fit test is positive $\left(\mathrm{F}_{0}=\right.$ $\left.55,03<\mathrm{F}_{(5,1,0.05)}=230.2\right)$ due to the very low $\mathrm{R}^{2}$ it can be decided that the first-order model is inadequate.
Table 3: ANOVA results for the first-order model Analysis of Variance

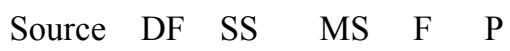

$\begin{array}{llllll}\text { Regr } & 3 & 4.3473 & 1.4491 & 1.57 & 0.291\end{array}$

Resi Err $6 \quad 5.52310 .9205$

Lack of Fit $5 \quad 5.5031 \quad 1.1006 \quad 55.03 \quad 0.102$

Pure Error $1 \quad 0.0200 \quad 0.0200$

Total $\quad 9 \quad 9.8704$

\subsection{Second Order Model}

After determining the first-order model is not adequate, the second order model is built. Since it is suitable for our model we used Box-Behnken design ( $3^{\mathrm{k}}$ factorial design). Table 4 shows $3^{3}$ factorial design points and the average number of buses obtained from simulation model of the production line. The second order model to fit the results of $3^{3}$ full factorial experimental design is given below:

$$
Y=\beta_{0}+\sum_{i=1}^{k} \beta_{i} x_{i}+\sum_{i} \sum_{\substack{j \\ i<j}} \beta_{i j} x_{i} x_{j}+\varepsilon
$$

The second order polynomial response function is given in Equation 4.

$$
\begin{aligned}
& Y=10.8333+0.59125 x_{1}+0.66625 x_{2} \\
& +0.225 x_{3}-0.621667 x^{2}{ }_{1}-0.971667 x^{2}{ }_{2} \\
& -0.169167 x^{2}{ }_{3}+0.11 x_{1} x_{2}+0.1575 x_{1} x_{3} \\
& -0.0075 x_{2} x_{3}+\varepsilon
\end{aligned}
$$

The validity of the model is shown by Lack of fit, F tests. The ANOVA results are given in Table 5.

The analysis of variance (ANOVA) reported in Table 5 shows that the second order regression model is significant. The $\mathrm{F}$ value of $8.64\left(\mathrm{~F}_{(9,5,0.05)}=4.77\right\}$ and $\mathrm{p}$-value of 0.014 demonstrate that the model is statistically significant at $95 \%$ confidence level. The analysis of variance also indicates that the model had no significant lack of fit $(9.90$ doesn't exceed $\left.F_{(3,2,0.05)}=19.16\right)$, which suggest that it adequately represents a true relationship between dependent and independent variables. Besides, the coefficient of determination, $\mathrm{R}^{2}$, is found to be 0.94 so it shows a sufficient agreement between experimental and predicted values. In conclusion, this second order model is accepted and the optimum level of the factors will be determined using this model. 
Table 4: $3^{3}$ factorial design

\begin{tabular}{|c|c|c|c|c|}
\hline $\begin{array}{c}\text { Desg. of } \\
\text { Exp. Points }\end{array}$ & $\mathrm{x}_{1}$ & $\mathrm{x}_{2}$ & $\mathrm{x}_{3}$ & $\begin{array}{c}\text { Ave. Daily } \\
\text { Output } \\
\text { (Number of } \\
\text { Buses) }\end{array}$ \\
\hline 1 & 0 & 1 & -1 & 10.20 \\
\hline 2 & -1 & 0 & 1 & 9.47 \\
\hline 3 & 0 & 0 & 0 & 10.70 \\
\hline 4 & 0 & 0 & 0 & 10.20 \\
\hline 5 & -1 & 1 & 0 & 9.53 \\
\hline 6 & 1 & 0 & 1 & 11.40 \\
\hline 7 & 0 & -1 & -1 & 9.07 \\
\hline 8 & -1 & 0 & -1 & 9.00 \\
\hline 9 & 0 & 0 & 0 & 10.80 \\
\hline 10 & -1 & -1 & 0 & 8.20 \\
\hline 11 & 1 & 0 & -1 & 10.30 \\
\hline 12 & 0 & -1 & 1 & 9.20 \\
\hline 13 & 1 & 1 & 0 & 10.50 \\
\hline 14 & 0 & 1 & 1 & 10.30 \\
\hline 15 & 1 & -1 & 0 & 8.73 \\
\hline
\end{tabular}

The surface map to the two factors considered is given in Figure 2 as an example to point out the simultaneous effects of the independent variables $\mathrm{X}_{1}, \mathrm{X}_{2}$ only.

Table 5: Analysis of Variance (ANOVA) results for the second -order model

\begin{tabular}{lllllll}
\hline Source & DF & Seq SS & Adj SS & Adj MS & F & P \\
\hline Regres & 9 & 11.5091 & 11.50909 & 1.27879 & 8.64 & 0.014 \\
Linear & 3 & 6.7527 & 6.75273 & 2.25091 & 15.21 & 0.006 \\
Square & 3 & 4.6085 & 4.60852 & 1.53617 & 10.38 & 0.014 \\
Interaction & 3 & 0.1478 & 0.14785 & 0.04928 & 0.33 & 0.803 \\
Resi Err & 5 & 0.7398 & 0.7398 & 0.14797 & & \\
Lack-of- & 3 & 0.6932 & 0.69317 & 0.23106 & 9.90 & 0.093 \\
Fit & & & & & & \\
Pure Error & 2 & 0.0467 & 0.04667 & 0.02333 & & \\
Total & 14 & 12.2489 & & & & \\
\hline
\end{tabular}

Table 6: The CI of number of buses obtained from simulation model

\begin{tabular}{lcccc}
\hline Factors & $\begin{array}{c}\text { Regression } \\
\text { Model }\end{array}$ & $\begin{array}{c}99.5 \% \mathrm{CI}_{\mathrm{L}} \\
\text { Simulation } \\
\text { Model }\end{array}$ & $\begin{array}{c}99.5 \% \mathrm{CI}_{\mathrm{U}} \\
\text { Simulation } \\
\text { Model }\end{array}$ & $\begin{array}{c}\text { Mean of } \\
\text { Simulation } \\
\text { Model }\end{array}$ \\
\hline $11,2,3$ & 11.1 & 11.080 & 12.314 & 11.7 \\
\hline
\end{tabular}

\subsection{Canonical Analysis}

The canonical analysis shows that the stationary point of the fitted response surface is $\mathrm{X}_{0}=\left(\mathrm{X}_{1}, \mathrm{X}_{2}, \mathrm{X}_{3}\right)=(11.25794$, $2.374,2.949)$ which yields predicted mean response of $\mathrm{Y}=11.25$, a maximum in the experimental region. If we take the combination of nearest integer values as $(11,2,3)$ the daily output is 11.1 buses according to the second-order regression model. If we take the combination of nearest largest integer values as $(12,3,3))$ the daily output is 10.8 buses. In this situation nearest integer value approach gives better solution as can be seen in Figure 2. The simulation model of the considered system with these configuration is then run and the results are given in Table 6. It is noted that from this table $99.5 \%$ confidence interval, obtained from the simulation model, contains the result predicted by second order regression metamodel, which is also a secondary validation step for the metamodel.

\section{CONCLUSION}

In this study, RSM is applied as a simulation optimization technique to a real world problem in an automotive industry in Ankara, Turkey. A simulation model is developed for investigating detailed production analysis and for evaluating new designs.

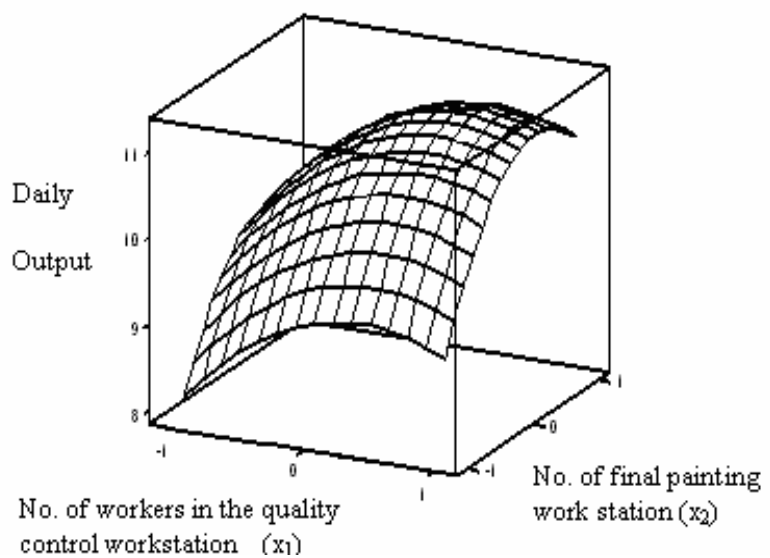

Figure 2. Response surface of number of buses produced daily as a function of the number of workers in the quality control workstation $\left(\mathrm{X}_{1}\right)$, the number of final painting workstation $\left(\mathrm{X}_{2}\right)$

The simulation model is validated using the date gathering from existing production lines in the paintshop. The model is used to obtain the number of buses produced daily and to determine the factors affecting this throughput. Based on the simulation and physical and economical conditions of the system, factors (the number of workers in the quality control workstation, the number of final painting workstation, the number of priming workstation) and allowable factor levels are determined. The RSM is used to 
find the optimum levels of considered factors to ensure well-designed physical system. In other words, simulation model and optimization stage integration is used both to analyze the performance of the current paint shop line to reveal the bottlenecks at some stages and determine the optimum working conditions, respectively, with reduced cost, time and effort. As a result, using the feasible configuration of the factors found to be $X_{1}=11, X_{2}=2, X_{3}=3$, gave maximum number of buses produced daily, so improved daily productivity in the system by $28 \%$.

\section{REFERENCES}

Allen T., and L. Yu. 2000. Low cost response surface methods for and from simulation optimization. In Proceeding of the 2000 Winter Simulation Conference, 704-714. Piscataway, New Jersey: Institute of Electrical and Electronics Engineers, Inc..

Angün, E., J. P. C. Kleijnen, D. Den Hertog,and G. Gürkan. 2002. Response surface methodology revisited. In proceeding of the 2002 Winter Simulation Conference, 377-383. Piscataway, New Jersey: Institute of Electrical and Electronics Engineers, Inc..

Box, G. E. P., and K. B. Wilson. 1951. On the experimental attainment of optimum conditions. Journal of the Royal Statistical Society Series B 13(1): 1-38.

Box G. E. P., W. G. Hunter, and J. S. Hunter. 1978. Statistics for Experimenters, An Introduction to Design Analysis and Model Building. New York: John Wiley $\&$ Sons.

Biles, W. E., J. P. C. Kleijnen. 1999. A Java-based simulation manager for optimization and response surface methodology in multiple-response parallel simulation. In Proceeding of the 1999 Winter Simulation Conference, 513-517. Piscataway, New Jersey: Institute of Electrical and Electronics Engineers, Inc..

Carson, Y., and A. Maria. 1997. Simulation optimization: methods and applications. In Proceeding of the 1997 Winter Simulation Conference, 118-126. Piscataway, New Jersey: Institute of Electrical and Electronics Engineers, Inc..

Kelton, D. W., R. P. Sadowski, and D. A. Sadowski. 1998. Simulation with Arena. International ed. McGrow-Hill.

Kenne, J. P., and A. Gharbi. 2001. A simulation optimization approach. Journal of Intelligent Manufacturing 12:421-431.

Law, A. M. 2007. Simulation Modeling and Analysis. $4^{\text {nd }}$ ed. McGraw-Hill,

Nicolai, R. P., R. Dekker, N. Piersma, and G. J. van Oortmarssen. 2004. Automated response surface methodology for stochastic optimization models with unknown variance. In Proceeding of the 2004 Winter Simulation Conference,491-498. Piscataway, New Jersey: Institute of Electrical and Electronics Engineers, Inc..
Schamburg, J. B., and D. E. Brown, 2004a. Simulated Annealing For Selection of Experimental Regions in RSM Applications. In Proceedings of the 2004a Winter Simulation Conference, 931-940. Piscataway, New Jersey: Institute of Electrical and Electronics Engineers, Inc..

Schamburg, J. B., and D. E. Brown. 2004b. Generalized multiple RSM for complex computer simulation applications. In Proceedings of the $2004 b$ Winter Simulation Conference, 958-966. Piscataway, New Jersey: Institute of Electrical and Electronics Engineers, Inc..

Stewart, P., P. J. Fleming, and S. MacKenzie. 2002. On The RSM And Designed experiments for computationally intensive distributed aerospace simulations. In Proceedings of the 2002 Winter Simulation Conference , 476-482. Piscataway, New Jersey: Institute of Electrical and Electronics Engineers, Inc..

\section{AUTHOR BIOGRAPHIES}

BERNA DENGIZ is the chair of Department of Industrial Engineering at the Baskent University. Her field of study is mainly modeling and optimization of complex large sized systems besides heuristic optimization. She has received research funding for her collaborative studies from TUBITAK (The Scientific and Technical Research Council of Turkey), Government Planning Center of Turkey and National Science Foundations (NSF) of the US.A. She has worked as visiting professor at the University of Pittsburgh and the Auburn Universities. Her web page can be found via <wWw. baskent. edu . tr/ bdengiz>.e-mail: $<$ bdengiz@baskent.edu.tr>.

ONDER BELGIN is Ms.C. student in the Department of Industrial Engineering at the Gazi University and working as an Industrial Engineer at the National Productivity Center of Turkey. e-mail: <obelgin @mpm. org. tr>. 